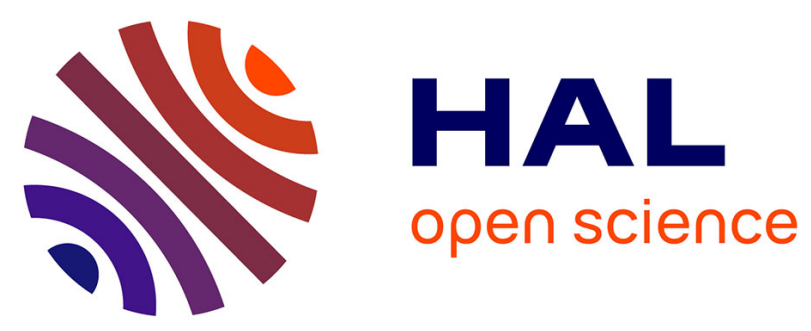

\title{
Effect of rhodium doping on the photorefractive properties of BCT crystals
}

Sylvie Bernhardt, H. Veenhuis, Philippe Delaye, Gérald Roosen

\section{To cite this version:}

Sylvie Bernhardt, H. Veenhuis, Philippe Delaye, Gérald Roosen. Effect of rhodium doping on the photorefractive properties of BCT crystals. Optical Materials, 2001, 18, pp.13-16. 10.1016/S09253467(01)00121-5 . hal-00674643v2

\section{HAL Id: hal-00674643 \\ https://hal-iogs.archives-ouvertes.fr/hal-00674643v2}

Submitted on 30 Mar 2012

HAL is a multi-disciplinary open access archive for the deposit and dissemination of scientific research documents, whether they are published or not. The documents may come from teaching and research institutions in France or abroad, or from public or private research centers.
L'archive ouverte pluridisciplinaire HAL, est destinée au dépôt et à la diffusion de documents scientifiques de niveau recherche, publiés ou non, émanant des établissements d'enseignement et de recherche français ou étrangers, des laboratoires publics ou privés. 
Paper reference number : J-I.6

\title{
Effect of rhodium doping on the photorefractive properties of BCT crystals
}

\author{
S.Bernhardt ${ }^{1 *}$, H.Veenhuis ${ }^{2}$, P.Delaye ${ }^{1}$, G.Roosen ${ }^{1}$ \\ (1) Laboratoire Charles Fabry de l'Institut d'Optique , Unité Mixte de Recherche 8501 du Centre National de la \\ Recherche Scientifique, Bat. 503, Centre Scientifique d'Orsay, B.P. 147, 91403 Orsay Cedex, France. \\ (2) Universität Osnabrück, FachBereich Physik, D 49069 Osnabrück, Germany
}

\begin{abstract}
We present an experimental investigation of the photorefractive properties of rhodium doped barium calcium titanate crystals of the congruently melting composition $\mathrm{Ba}_{0.77} \mathrm{Ca}_{0.23} \mathrm{TiO}_{3}$. We have studied the photorefractive properties of several crystals (undoped, rhodium or iron doped). All the crystals are sensitive in the infrared region $(\lambda=850 \mathrm{~nm})$. We have found that a three level model of photorefraction is necessary to explain the experimental results. This study has put forward the fact that the BCT crystals that we have studied contain a large amount of iron, which damages the good photorefractive properties of the crystal. Indeed, the high intensity needed to saturate the gain $\left(\mathrm{I}_{\text {sat }}>\right.$ $1 \mathrm{~W} / \mathrm{cm}^{2}$ ), which is an important drawback for many applications, seems to be due to iron.
\end{abstract}

Keywords : photorefractive crystals, two-beam coupling.

\section{Introduction}

$\mathrm{BaTiO}_{3}: \mathrm{Rh}$ is of special interest for many applications because of its good infrared sensitivity. The photorefractive effect is governed by rhodium, which appears under three states of charges : $\mathrm{Rh}^{3+}$, $\mathrm{Rh}^{4+}$ and $\mathrm{Rh}^{5+}[1]$. But it suffers from a drawback that prevents its use in industrial systems : a phase transition at $5^{\circ} \mathrm{C}$.

Recently, first results about $\mathrm{Ba}_{0.77} \mathrm{Ca}_{0.23} \mathrm{TiO}_{3}$, which has no phase transition at room temperature, were published and show that this crystal has high electrooptic coefficients and high gain in the visible region $[2,3]$. BCT:Rh may thus be an alternative to $\mathrm{BaTiO}_{3}: \mathrm{Rh}$, provided it is sensitive in the infrared region. In this paper, we will focus on the photorefractive properties of this new material.

\footnotetext{
* Corresponding author : tel : 331693587 38, fax : 331693587 00, email : sylvie.bernhardt@iota.u-psud.fr.
} 
Absorption and two-beam coupling gain measurements are carried out in order to find out whether rhodium doping improves the photorefractive performances of BCT.

\section{Experimental results}

\subsection{Crystals}

BCT crystals with $0,220,370,600,1000$ and $2000 \mathrm{ppm}$ of rhodium and $140 \mathrm{ppm}$ of iron in the melt are studied. Typical dimensions are $2 * 3 * 4(=\mathrm{c}) \mathrm{mm}^{3}$.

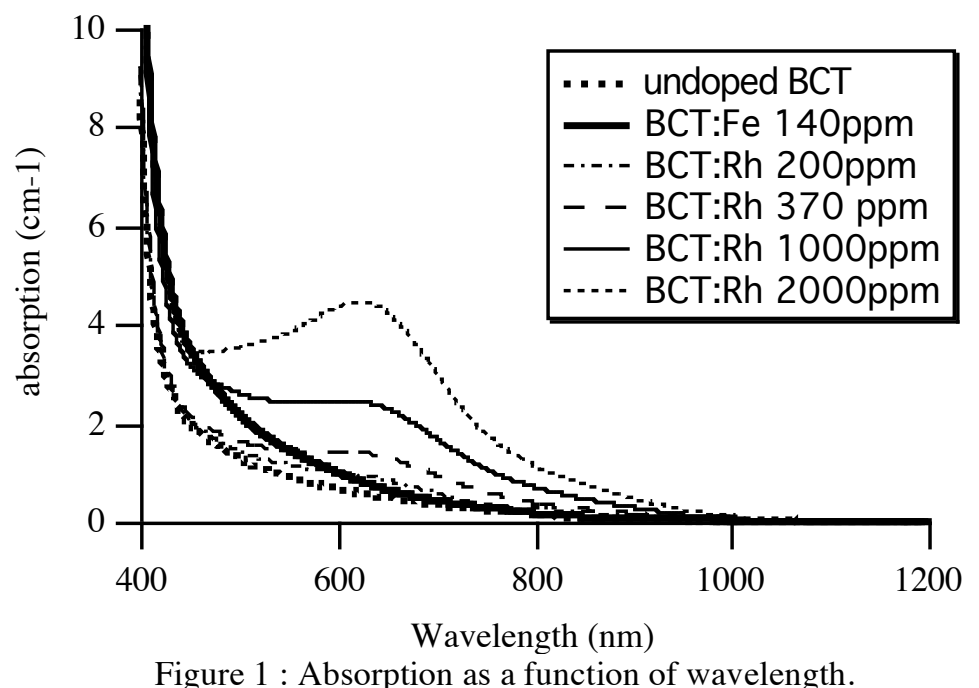

The absorption spectra are presented in Fig.1. The influence of rhodium on absorption is the same as in $\mathrm{BaTiO}_{3}: \mathrm{Rh}$ with a large absorption band around $600 \mathrm{~nm}$. This absorption band is proportionnal to the amount of rhodium in the BCT:Rh crystals. However, we point out that the absorption spectra for the undoped and the iron doped crystals are similar.

\subsection{Two-beam coupling experiments}

We carried out two kinds of measurements of the photorefractive gain. Firstly, we studied the dependance of the gain with the grating spacing. Secondly, we measured the photorefractive gain as a function of light intensity. In all experiments, we used a DBR laser diode at $850 \mathrm{~nm}$. From the steady state intensities of the transmitted weak signal beam without and with illumination by the pump beam, we calculate the two beam coupling coefficient. Each measurement datum corresponds to a measurement in attenuation and in amplification allowing to separate the photorefractive contributions from an eventual absorption component (induced absorption or absorption grating). The incident beams enter the crystal symmetrically.

Two-beam coupling measurements versus the grating wave vector were carried out for ordinary polarization (Fig.2a). We checked that the laser intensity was sufficient to saturate the photorefractive gain in all experiments. 

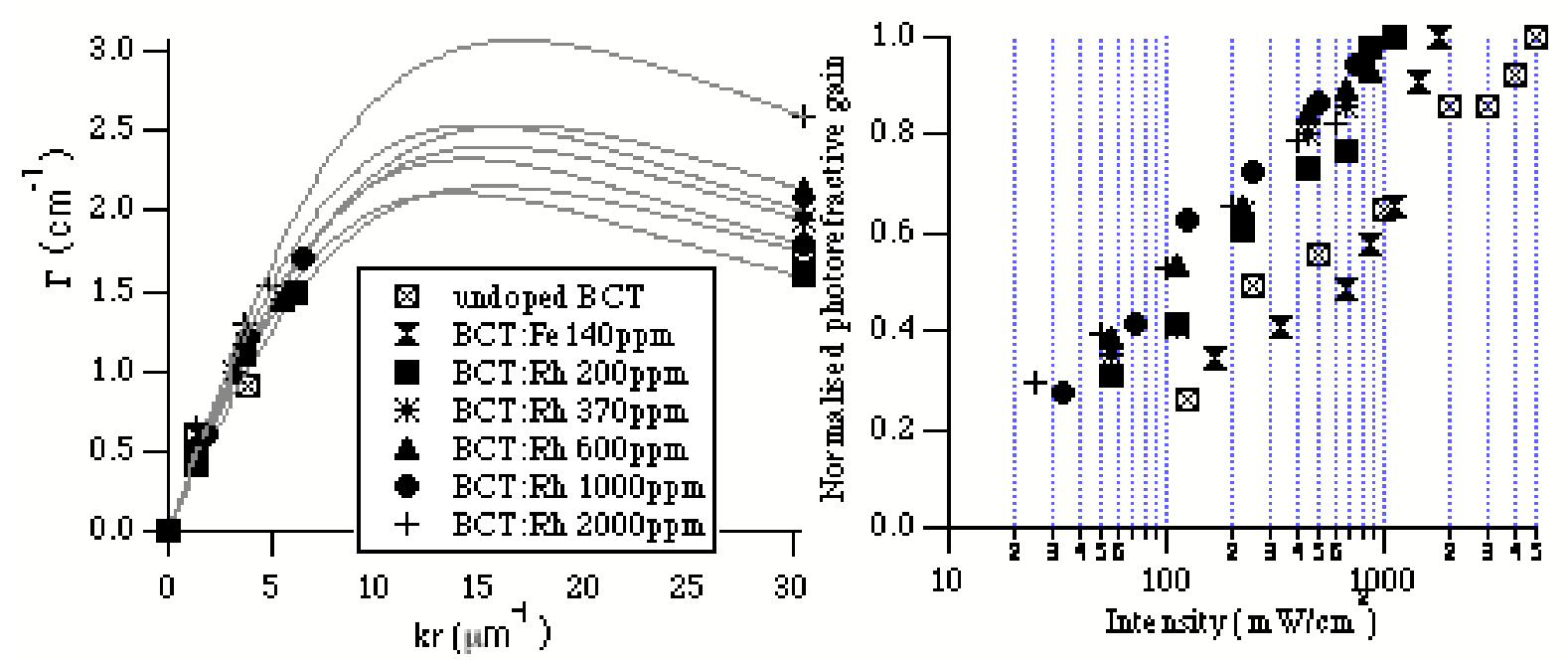

Figure 2 (a) Photorefractive gain in ordinary polarization as a function of the grating wave vector.(b) Normalized photorefractive gain as a function of intensity

We deduced from these experiments the value of the effective trap density $\mathrm{N}_{\text {eff }}=(8 \pm 2) \cdot 10^{22} \mathrm{~m}^{-3}$, which is almost constant for all crystals .

Gain as a function of incident illumination was also measured (Fig.2b). We found that the intensity necessary to saturate the gain $\left(\mathrm{I}_{\mathrm{sat}}\right)$ increases when the quantity of rhodium decreases and is even higher for the undoped and iron doped samples. Furthermore, $\mathrm{I}_{\text {sat }}$ is 1000 time higher in BCT:Rh than in $\mathrm{BaTiO}_{3}: \mathrm{Rh}$. This is an important drawback for many applications.

\section{Discussion about the charge transport model}

To explain our experimental results, we considered several models of charge transport, beginning with the most simple, and checked if they fulfilled the following conditions :

- the effective trap density is almost independent of the amount of rhodium doping.

- the iron doped and undoped samples are sensitive at $850 \mathrm{~nm}$.

- the intensity necessary to saturate the gain increases when the amount of rhodium decreases.

\subsection{Two-level model with three-charge states of rhodium}

It is established that the properties of $\mathrm{BaTiO}_{3}: \mathrm{Rh}$ in the infrared region are well described by a twolevel model with three states of charge of rhodium $[1,4]$.

To explain the charge transport in BCT:Rh, we first try to use the same model. We performed numerical simulations in order to see if we can explain the experimental results with this model. Many material parameters (such as the photoionization cross sections, the thermal ionization rates, the compensation density and the total amount of rhodium) are unknown for BCT and we first used the parameters we have determined for $\mathrm{BaTiO}_{3}: \mathrm{Rh}$ in other experiments. Then we varied the values of these parameters around the initial ones. But we never found a set of parameters that fulfilled the first condition. Furthermore, this assumption cannot explain the fact that the iron doped and undoped crystals are sensitive at $850 \mathrm{~nm}$.

\subsection{Rhodium is an acceptor, one-level model of photorefractivity}

Another possibility was that rhodium does not contribute directly to the photorefractive effect but was only an acceptor. We first supposed that the photorefractive effect was governed by the simpliest model: a one-center model [5] (may be $\mathrm{Fe}^{3+/ 4+}$ ). But in a one-level model, the effective trap density 
expresses analitically and always depends on the compensation density. If rhodium acted as an acceptor, it would change the compensation density and thus the effective trap density. This is in contradiction with the first condition.

\subsection{Rhodium is an acceptor, two-level model with three states of charge}

As a one-center model did not explain our results, we performed numerical simulations of a two-level model (may be $\mathrm{Fe}^{3+/ 4+}$ and $\mathrm{Fe}^{4+/ 5+}$ ). To simulate a variation of the amount of rhodium in the crystal, we changed the compensation density and then the effective trap density changed and $\mathrm{I}_{\text {sat }}$ varies in a way that was in contradiction with the experimental results.

\subsection{Three level model : three states of charge of rhodium, two states of charges of iron}

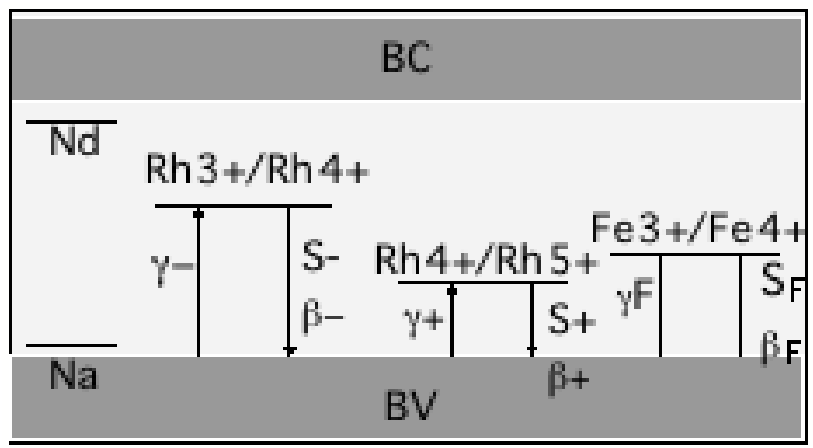

Figure 3 : Schematic energy level diagram of BCT:Rh.

This assumption is based on two observations. Firstly, the absorption band in the near infrared shows that absorption increases proportionally to the amount of rhodium and that the undoped sample has almost the same absorption spectra as the iron doped. Secondly, both the undoped and the iron doped crystals are sensitive in the infrared. That is why we considered that both rhodium and iron participate in the photorefractive effect in BCT:Rh, iron being the center supposed to participate in the photorefractive effect in the undoped and iron doped samples (Fig.3). Numerical simulations of this three-level model [6] led us to a set of parameters that enables to fit our experimental results (Fig.4).
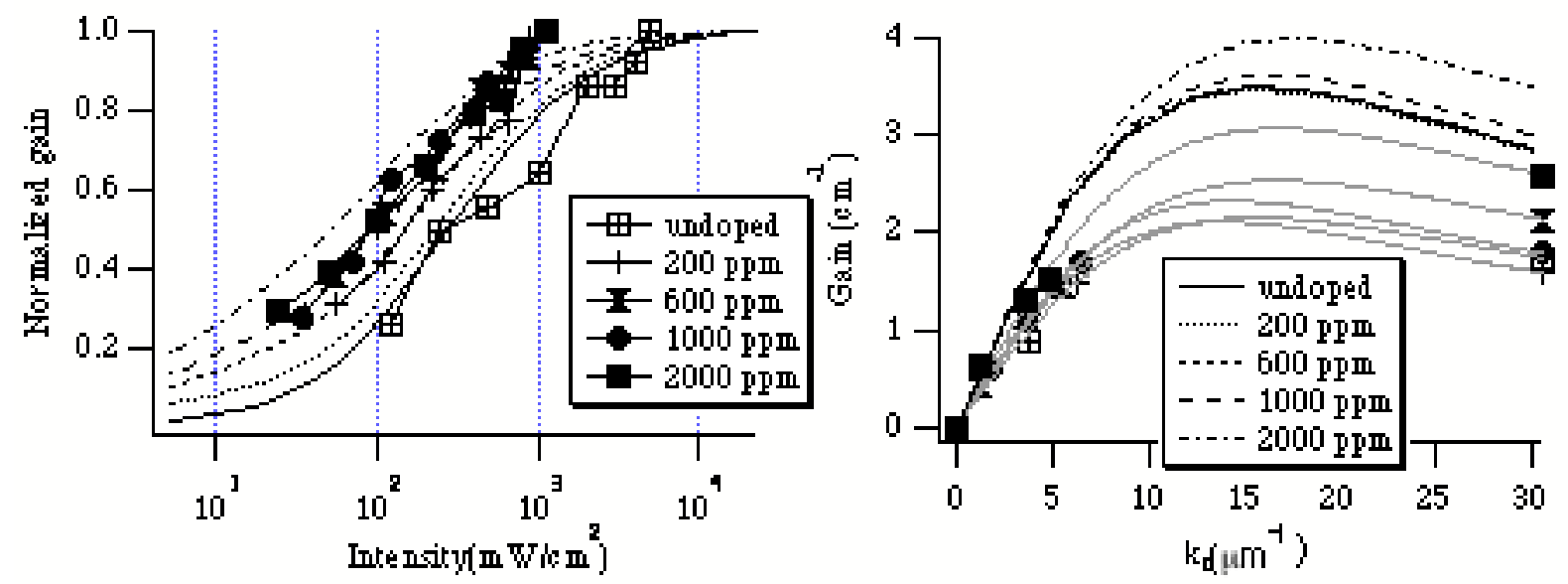

Figure 4 : comparison between experimental and simulated curves

\section{Conclusion}


The BCT:Rh crystals we have studied seem to contain a lot of iron. Indeed, a three level model with two levels of rhodium and one level of iron is necessary to explain the experimental results. The presence of iron may be responsible for the high $\mathrm{I}_{\text {sat }}$, which is a drawback for future applications of this crystal. Indeed, numerical simulations show that dividing the quantity of iron by 50 reduces $\mathrm{I}_{\text {sat }}$ by a factor of $10^{4}$.

\section{References}

[1] H.Kröse, R.Scharfschwerdt, O.F.Schirmer, H.Hesse, "Light-induced charge transport in $\mathrm{BaTiO}_{3}$ via three charge states of rhodium", Appl. Phys. B 61, 1 (1995).

[2] Ch.Kuper, K.Buse, U.Van Stevendaal, M.Weber, T.Leidlo, H.Hesse, E.Krätzig, "Electrooptic and photorefractive properties of ferroelectric barium-calcium titanate crystals", Ferroelectrics 208-209, 213 (1998)

[3] S.Bernhardt, P.Delaye, H.Veenhuis, G.Roosen, "Photorefractive two-beam coupling characterization of a barium-calcium titanate crystal", Appl. Phys. B, to be published.

[4] N.Huot, J.M.C.Jonathan, G.Roosen, "Validity of the three charge state model in photorefractive $\mathrm{BaTiO}_{3}: \mathrm{Rh}$ at $1.06 \mu \mathrm{m}$ in the cw regime", Appl. Phys. B. 65, 486 (1997).

[5] N.V.Kukhtarev, V.B.Markov, S.G.Odulov, M.S.Soskin and V.L.Kinetskii, "Holographic storage in electrooptic crystals. I. Steady State", "Holographic storage in electrooptic crystals. II. Beamcoupling light amplification", Ferroelectrics 22, 949 (1979).

[6] L.Corner, R.Ramos-Garcia, A.Petris, M.J.Damzen, "Experimental and theoretical characterization of rhodium doped barium titanate", Opt. Comm. 143, 165 (1997). 